\title{
EXPERIMENTAL METHOD ON INVESTIGATION OF FIBRE REINFORCED CONCRETE AT ELEVATED TEMPERATURES
}

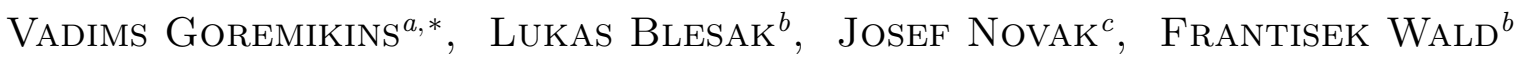 \\ ${ }^{a}$ Riga Technical University, Institute of Structural Engineering and Reconstruction, Riga, Latvia \\ ${ }^{b}$ Czech Technical University in Prague, Department of Steel and Timber Structures, Prague, Czech Republic \\ ${ }^{c}$ Czech Technical University in Prague, Department of Concrete and Masonry Structures, Prague, Czech Republic \\ * corresponding author: goremikins@gmail.com
}

\begin{abstract}
Generally speaking, adding a certain amount of steel fibres to a concrete mixture improves its mechanical properties. Currently, a lack of information considering tensile and post cracking behaviour of FRC at elevated temperatures is an issue to be faced. An experimental study of steel fibre reinforced concrete, also containing polymer fibres (FRC), subjected to high temperature is presented herein. Compressive strength, split tensile strength and ultimate bending strength were evaluated. Specimens were heated by the use of ceramic heaters and repacked for testing consequently. A finite-element based model was developed to predict the temperature distribution inside a specimen during both the heating and the cooling process.
\end{abstract}

KEYWORDS: temperature distribution; elevated temperature; four-point bending test; compressive and tensile tests.

\section{INTRODUCTION}

The research presented herein leads to a proper description of fibre reinforced concrete behaviour under the actions of elevated temperature and understanding its behaviour in specific conditions. A proper material definition of FRC makes it applicable not only by scientists but also by designers and engineers [1] in the field of civil engineering practice. Making FRC material parameters applicable in civil engineering enables to design and so assemble more durable and cost effective structures 2. Several models of a post-crack behaviour for FRC have been developed so far, whilst new material models are still being developed [3, 4].

In spite of several advantages of FRC for enhancement the sustainability, load carrying capacity, and ductility of structures, there is still no sufficient knowledge regarding tensile and post cracking behaviour of FRC at elevated temperatures, caused by fire. The behaviour of FRC concrete in compression, at elevated temperature, could be assumed as being identical as the plain concrete mixture and is described in a number of papers [5, 6], so as in the design codes. This paper is focused on describing the behaviour of FRC in tension at elevated temperature, where especially fibres are of an essential importance. The experimental data that have been acquired so far, are limited to a several mixtures of fibre content, fibre type, concrete class and other parameters [7, 8]. In order to reach reliable data, proper experimental measurements need to be delivered, all the possible mistakes need to be limited to minimum, maximal homogeneity in the FRC mixture must be provided, as well as a proper heating procedure and other phenomena need to be focused on. Different heating and testing methods were proposed by research teams 9,10 .

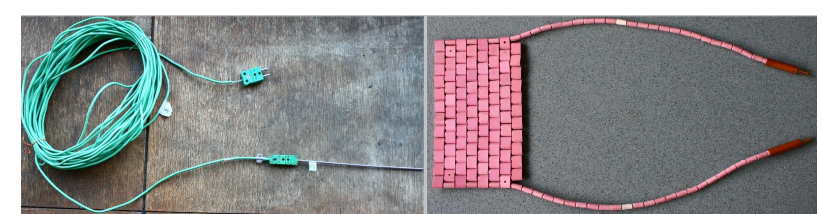

FiguRE 1. K-type thermocouple and ceramic heater.

This research is a continuation of a previous one, based on a numerical modelling of FRC behaviour, whilst all the data gained from the experiment were parallelly compared to the ones reached by modelling, taken from the reference and other literature.

In this paper, experimental method on investigation of FRC in elevated temperatures is described; other numerical data and reliable results will be further published.

\section{HEAT TRANSFER TEST}

\subsection{EXPERIMENT SETUP}

An important part of the research is a developing of the procedure of concrete specimen heating. The aim of this task is to determine a proper heating time period, necessary for specimen reaching an intended temperature and to achieve an uniform temperature distribution throughout the specimen. A special system, consisting of ceramic heaters and thermocouples (Fig. 1) coupled with a control machine Mannings HTC $70 \mathrm{~kW}$, was used for the heating procedure. Heat transfer test was performed with a pilot cube, dimensioned as $150 \times 150 \times 150 \mathrm{~mm}$. Three holes $75 \mathrm{~mm}$ long for the thermocouples assembly were drilled to monitor temperatures in the centre of the cube and 10 $\mathrm{mm}$ far from the surface. The prepared specimen was 


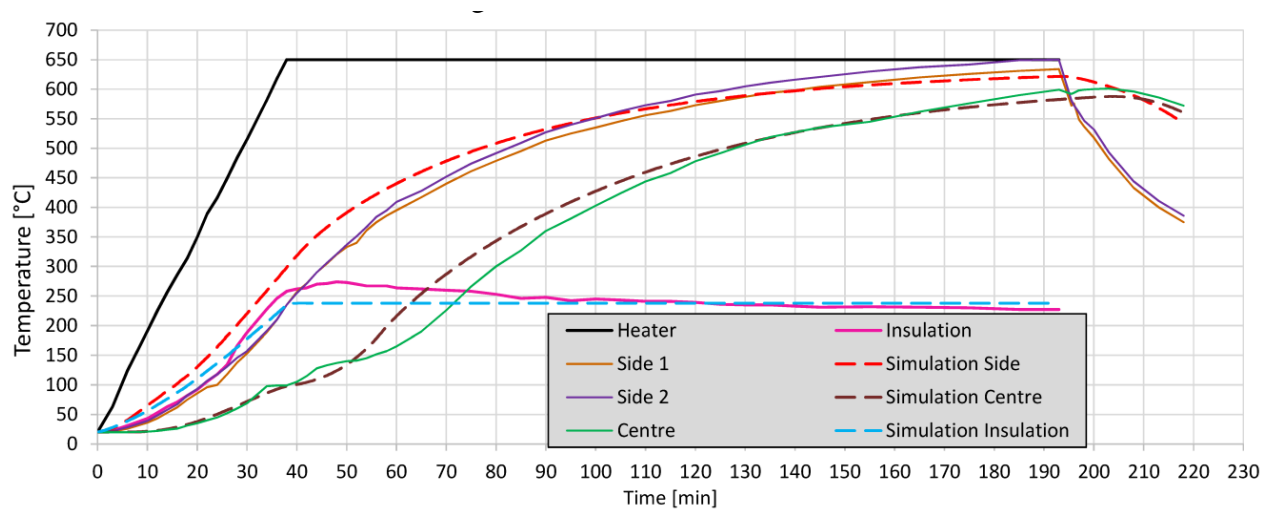

FiguRE 3. Heat transport during heating process.

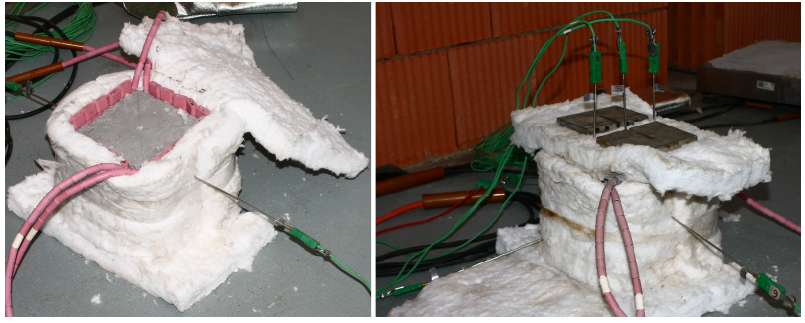

Figure 2. Testing setup of pilot cube aiming to observe temperatures inside a cube.

covered by two ceramic heaters in direct contact with the subjected specimen. A high-temperature-resistant glass wool insulation thermo-box was specially created, to ensure heat accumulation and also, to fix the heaters position. The temperature was controlled by thermocouples inside the specimen, on the surface of the heaters and on the surface of thermos-box (Fig. 2).

The ceramic heaters were heated up to $650^{\circ} \mathrm{C}$ by speed of heating equal to $1000^{\circ} \mathrm{C}$ per hour. The process of heating, as well as the temperature distribution within the specimen, in time, do not show any significant irregularities (Fig. 3). The temperature on the surface of ceramic heaters increased up linearly to the temperature equal to $650^{\circ} \mathrm{C}$ in 39 minutes, since the start of heating process. Then the temperature of heaters was kept constant until the temperature $600{ }^{\circ} \mathrm{C}$ was reached in the centre of a specimen. The temperature inside the specimen was controlled by the control machine, using data received by the thermocouples embedded previously. The heating time necessary to reach a constant temperature field within a specimen was defined to be equal to 193 minutes. After this phase, the heating process was stopped and thereby a specimen started to be cooled. It is important to mention that a specimen was removed from the thermo-box using fireproof gloves, repacked in a new glass-wool protection and placed on steel plates provided with an insulation layer. Reason for such a process was to simulate the steps, necessary to perform the process of compressive and split tension test on a heated specimen. During the cooling process, it is evident that the decrease in temperature on the specimen surface is more significant than in its core. Following the results, the maximum allowable time period for the static testing was determined, in order to avoid an excessive loss of temperature within a specimen.

\subsection{Simulation of heat transfer}

The process of heat transfer was modelled using FEM based software package ANSYS 16.2. SOLID70 8 nodes solid elements were used for modelling concrete, insulation and steel plates as well. Material characteristics according to EN 1992-1-2 11] and 19931-3 12 were used for the material models of concrete and steel, respectively. Lower limit of thermal conductivity was used for concrete. Thermal insulation with density equal to $80 \mathrm{~kg} / \mathrm{m}^{3}$, specific heat capacity equal to $840 \mathrm{~J} / \mathrm{kg} / \mathrm{K}$ and temperature dependent thermal conductivity, expressed by the equation $K=3.46994 \cdot 10^{-7} \Theta^{2}+1.29616 \cdot 10^{-4} \Theta+3.23192 \cdot 10^{-2}$ (where $\Theta$ is temperature in ${ }^{\circ} \mathrm{C}$ ) was used for simulation. The heating process was modelled by applying temperature to the areas separating thermal insulation and concrete (see Fig. 4). The convection and radiation boundary condition was applied to the external layers of thermal insulation. Process of repacking of the sample, done in the 193th min., was modelled by changing the material of the top and bottom layers of thermal insulation to steel and setting the temperature of insulation and steel plates to ambient temperature (Figs. 5 and 6). The temperature distribution within a sample at the end of the experiment in 218th min. is depicted in Fig. 7. Temperature development of monitored points in time at the experiment and FEM based simulation is shown in Fig. 3 .

The simulation results are close to the experimental ones. Temperature difference between the numerical simulation results and experimental results in the point positioned $10 \mathrm{~mm}$ far from the surface of the specimen at the starting phase of the experiment is explained by the not ideal contact between heaters and concrete surface. In the cooling phase, the variations for the same points are explained by the fact that the thermocouples were removed from the pre-drilled 


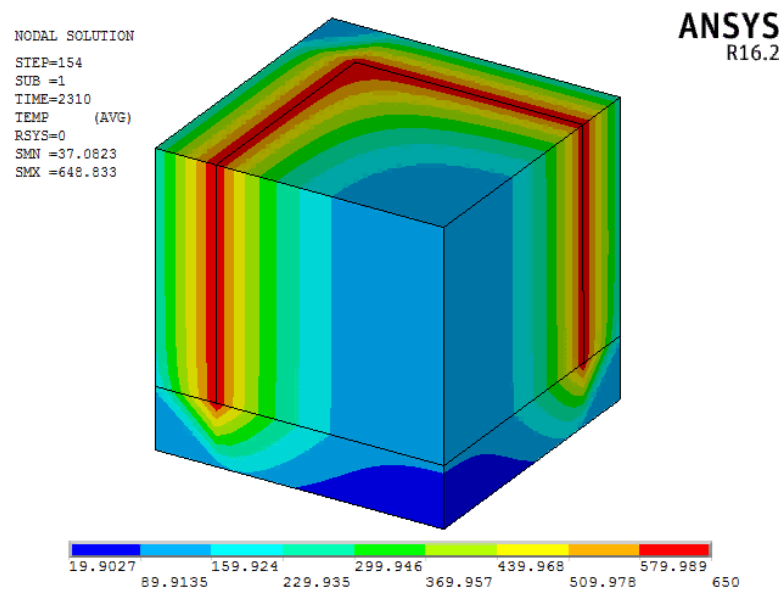

FIGURE 4. Distribution of temperature in simulation, at 39 min. A quarter view.

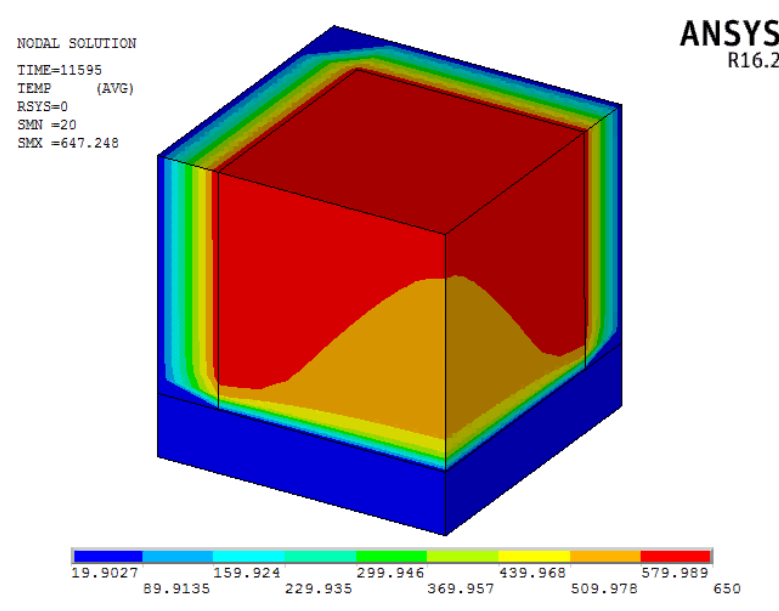

FiguRE 6. Distribution of temperature in simulation, at 193.25 min. A quarter view.

holes during repacking and ambient-temperature air penetrated inside the holes. Temperature of the outer insulation layer reached $238^{\circ} \mathrm{C}$ temperature and remained constant. Similar temperature development for insulation was observed in the experiment.

\section{Static LOADing Tests}

\subsection{CONCRETE COMPOSITION AND TEST SPECIMENS}

Fibre reinforced concrete, with strength class C45/55 of the parent concrete, was used for the static loading tests. The age of concrete specimens is equal to 69 months. The concrete specimens were kept under normal moisture conditions after first month of their production. The moisture content was not measured. The mixture consists of widely-used and available components, listed in Table 1. Polypropylene fibres were added to prevent concrete surface spalling [13].

The four point bending test was performed on the beams notched in the mid-span. Usage of the beams

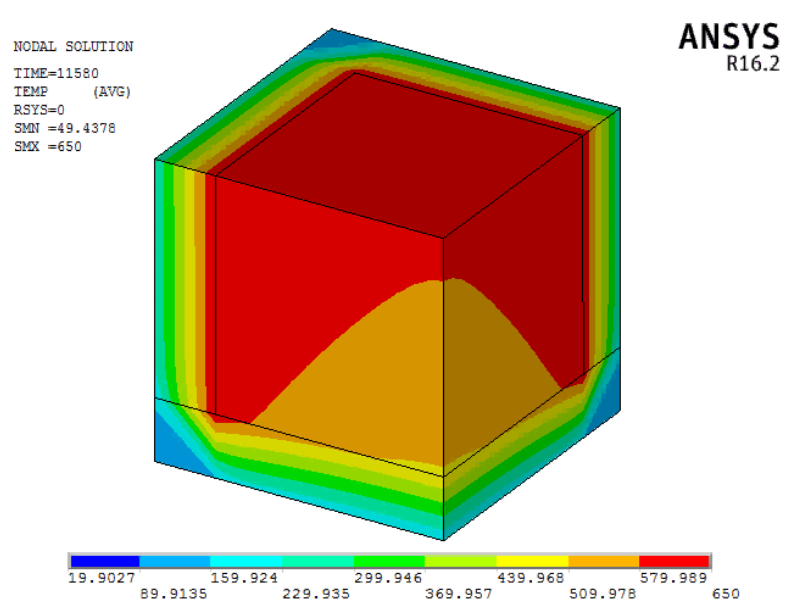

FiguRE 5. Distribution of temperature in simulation, at 193 min. A quarter view.

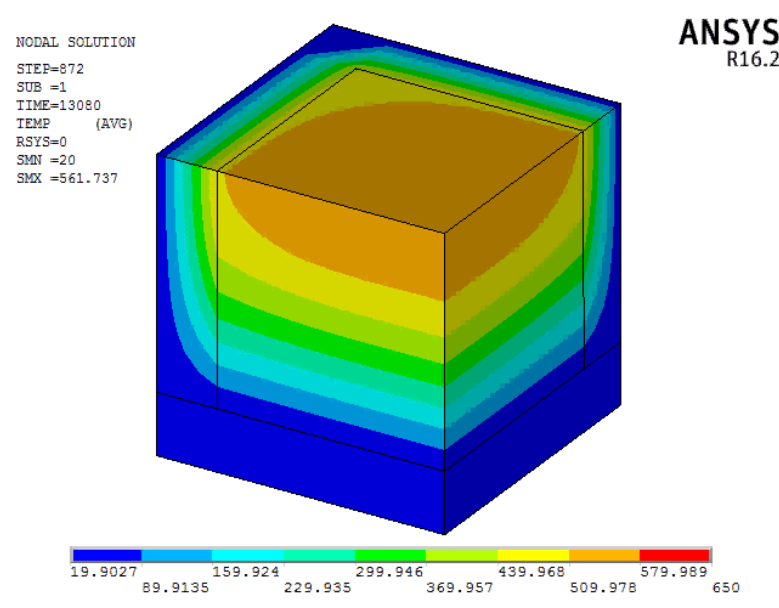

Figure 7. Distribution of temperature in simulation, at $208 \mathrm{~min}$. A quarter view.

\begin{tabular}{lc}
\hline Composition & Content $\left[\mathrm{kg} / \mathrm{m}^{3}\right]$ \\
\hline CEM I 42,5R Mokrá & 330 \\
Aggregate 0/4 mm Suchdol & 948 \\
Aggregate 8/16 mm Nemojov & 669 \\
Addition of fly ash Mělník & 140 \\
Addition ViscoCrete & 3.96 \\
Water & 190 \\
Steel fibre HE 75/50 Arcelor & 70 \\
Polypropylene fibre & 1.5 \\
\hline
\end{tabular}

TABle 1. Composition of the tested steel fibre reinforced concrete.

with a notch leads to a localization of the first flexural crack position, which's development was one of the main subjects of the performed test. Overall, there were 11 beams tested under various temperature conditions. The static compression test and split tension test of FRC was performed on cubes, which were cut out of spare prisms using a diamond saw. 


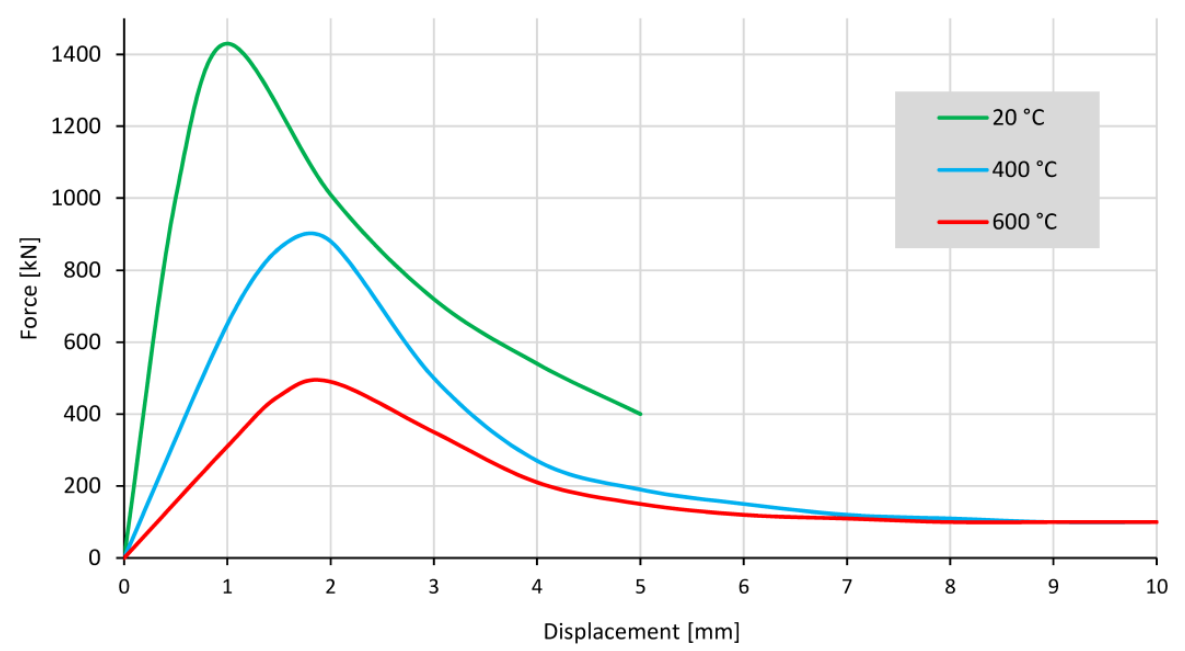

FiguRE 8. Force-displacement diagrams of the concrete specimens in compression.

\subsection{COMPRESSION TEST OF CONCRETE}

In compliance with CSN EN 12390-3:2012 [14 the static loading test was conducted on the cubes with dimensions $150 \times 150 \times 150 \mathrm{~mm}$ under $20^{\circ} \mathrm{C}, 400{ }^{\circ} \mathrm{C}$ and $600^{\circ} \mathrm{C}$ temperature. Tests were performed on overall 12 specimens. The whole set was divided into three groups based on the temperature of the particular specimen during the test. The specimens tested under elevated temperature were heated up to the intended temperature, by the procedure used during the test of heat transport. First the specimens were wrapped by the ceramic heaters, and then placed into a thermobox, made out of glass wool (Fig. 2). Thermocouples were located on the ceramic heaters surface, with the aim to record the temperature development during the heating procedure. The heating time, determined by the heat transport test, was equal to 193 minutes. After the intended time, temperature was uniformly distributed inside a specimen. The compression test was performed in a testing machine Inova $200 \mathrm{~F}$. In the case of the heated specimens, it was essential to limit the testing time in order to avoid excessive cooling of specimens. The compression test was controlled by the speed of deformation, equal to $0.02 \mathrm{~mm} / \mathrm{sec}$ in the range of deformation $0-7 \mathrm{~mm}$ and $0.1 \mathrm{~mm}$ for deformation bigger than $7 \mathrm{~mm}$. The force and deformation were recorded during the test parallel. The obtained data were used for creating force-displacement diagrams (Fig. 8) which describe the behaviour of the specimens.

\subsection{SPLIT TENSION TEST}

Split tension test was performed on cubes $150 \times$ $150 \times 150 \mathrm{~mm}$ in compliance with CSN EN 123906: 2010 [15]. Altogether, 12 specimens were tested under the actions of $20^{\circ} \mathrm{C}, 400{ }^{\circ} \mathrm{C}$ and $600{ }^{\circ} \mathrm{C}$ temperature. The subjected cubes were also divided into three groups. Eight specimens were tested under an elevated temperature and four specimens were tested under an ambient temperature as a reference point. The specimens were heated up, following the procedure used during the heat transport test. When the intended temperature was reached and uniformly distributed within the whole specimen, the split tension test was performed. It was essential to keep the testing time under 15 minutes in order to avoid the excessive loss of temperature in the specimens. The test, in testing machine Inova $200 \mathrm{~F}$, was performed as a deformation-controlled with loading speed equal to $0.02 \mathrm{~mm} / \mathrm{sec}$ in the range of deformation $0-7 \mathrm{~mm}$ and $0.1 \mathrm{~mm}$ for the deformation bigger than $7 \mathrm{~mm}$. The averaged force-displacement diagrams of specimens in split tension for ambient and elevated temperature are depicted in Fig. 9

\subsection{Four POINT BENDING TEST}

Four-point bending test was conducted on notched prisms, with the aim to obtain FRC material behaviour, including its peak and post cracking strength. Prisms dimensioned as $700 \times 150 \times 150 \mathrm{~mm}$ were provided with a notch $48 \mathrm{~mm}$ deep and $4.6 \mathrm{~mm}$ wide, located in the mid-span. In the preparation phase, a notch was cut and then all the prisms were measured and weighted. The dimensions of the prisms were determined in three positions, with the precision $0.01 \mathrm{~mm}$. The average values were used for a further evaluation. The load was applied in distance $100 \mathrm{~mm}$ from the mid-span on each side, through a steel frame. The distance between the supports was equal to $600 \mathrm{~mm}$. The tests of prisms were performed under an ambient $\left(20^{\circ} \mathrm{C}\right)$ and an elevated $\left(400{ }^{\circ} \mathrm{C}\right.$ and $600^{\circ} \mathrm{C}$ ) temperature, when four prisms of the whole set were used for each temperature. The tests were driven by displacement applied to a specimen through a hydraulic jack. The machine recorded the displacement and force. The crack opening displacement was recorded by the high speed camera Allied Vision Prosilica GT 200, with the speed $53.7 \mathrm{fps}$ (Fig. 10) which 


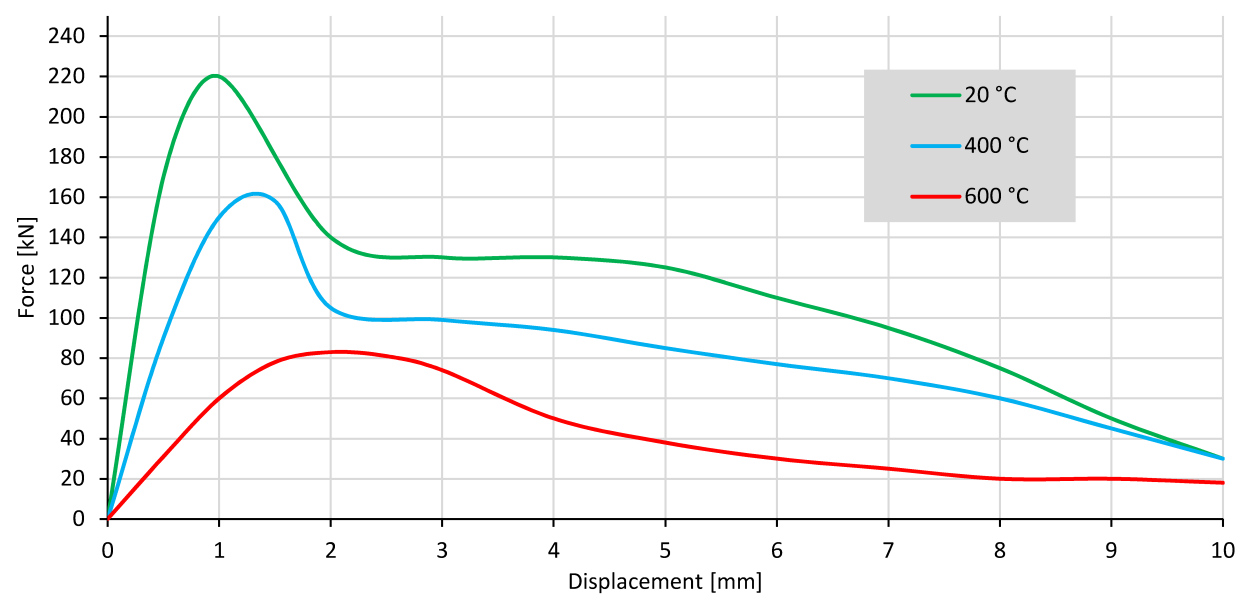

FiguRE 9. Force-displacement diagrams of concrete specimens in split tension.

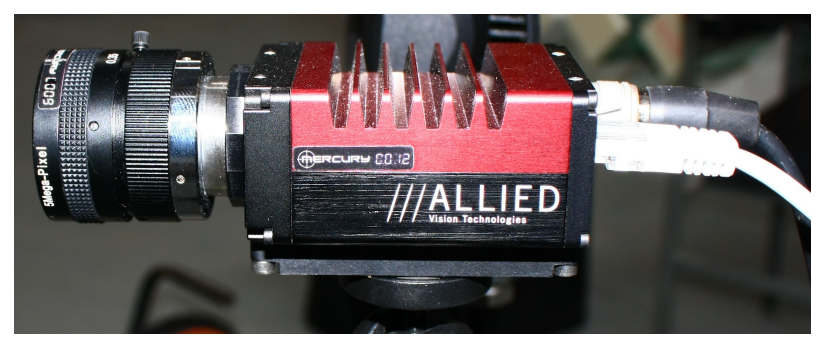

Figure 10. High speed camera Allied Vision Prosilica GT 2000 .

monitored the position of two points, marked on the specimen by high temperature resistant paint. Mutual distance of the points were continuously monitored and recorded during an experiment. The marks were located $1 \mathrm{~mm}$ above the peak of the notch and the initial horizontal distance between them was equal to $50 \mathrm{~mm}$. The camera was provided with Software Mercury RT 2.3. The measurements of the displacement, force and crack opening were connected together and a parallel output was received.

Five electrical ceramic heaters were used for the heating process. Two of them were installed at the bottom and three at the top of each prism. The temperature of the specimens was controlled by four thermocouples attached to a specimen surface. During the heating process, as well as the static test, the prisms were wrapped in a glass-wool insulation (Fig. 11), in order to eliminate thermal losses. Heating the specimens up to the intended temperature took four hours [16. The accuracy and suitability of the heating process were verified during the heat transfer test conducted on a pilot cube. The heat transfer test showed that after four hours of heating, the temperature was constant both in the core and on the surface of the heated specimen.

Afterwards, four point bending test was performed on the heated specimens. The steel supports as well as the steel loading frame were installed directly on the tested prisms. Thereby, the concrete-steel con-

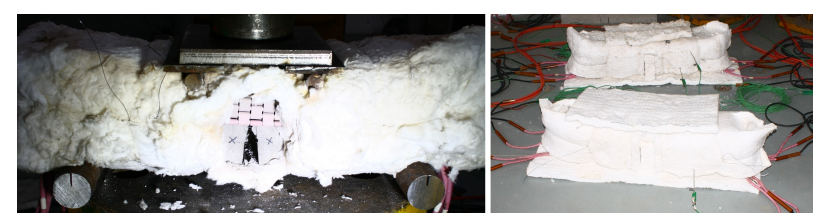

Figure 11. Prism specimens during testing (left) and heating (right) process.

tact excluded any unexpected deformation, caused by thermal insulation being compressed. Fig. 12 presents dependences of the bending force on the displacement of concrete prisms at ambient and elevated temperatures.

The cracks propagation, their number, direction and position were diverse for each prism and thus hardly predicted. This phenomenon is mainly caused by non-homogeneity of the tested material, particularly the number of fibres right above the notch has significant influence on the crack development. Ratio of compressive, splitting tensile strength and bending force at specified temperature over that of ambient temperature for tested FRC as a function of temperature is presented in Fig. 13. The obtained ultimate compression strength at elevated temperature is smaller than the one defined in EN 1992-1-2 [11.

\section{Conclusions}

Steel fibre reinforced concrete was experimentally tested under ambient and elevated temperature. The testing procedure introduced herein includes determining heating time by a pilot cube testing and measuring temperatures inside the concrete mixture, testing of concrete cubes in compression and split tension and notched prisms in four point bending at ambient and elevated temperature. The developed FEM based model allows predicting the heat transport inside the FRC specimen during the heating and cooling procedure. The testing procedure can be used to determine the material properties under the actions of an elevated temperature. Compressive strength of FRC is 


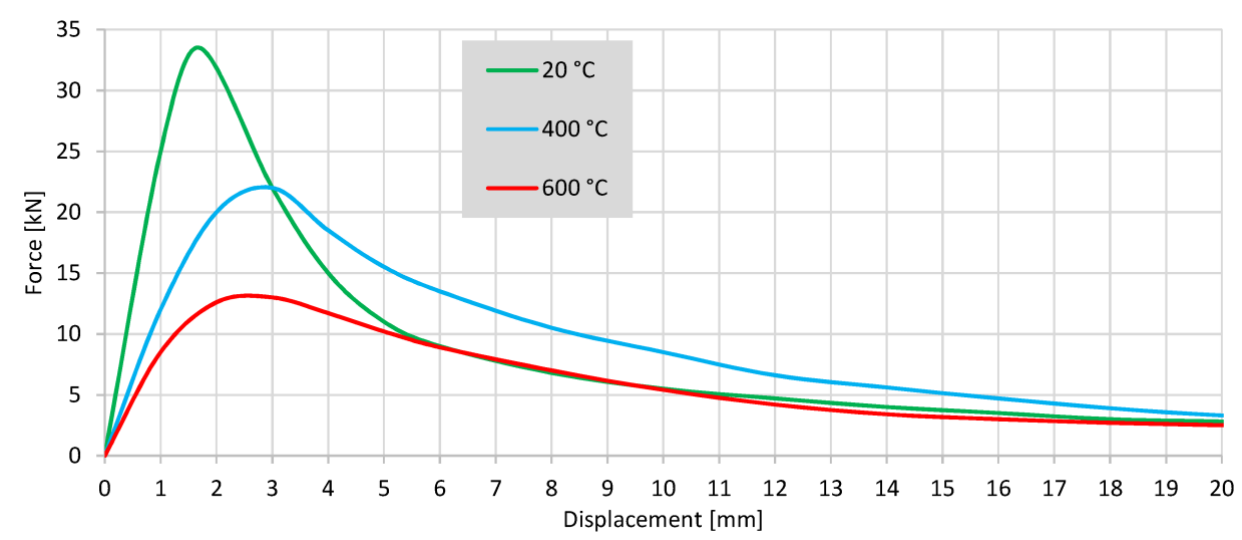

FigURE 12. Force-displacement diagrams of concrete prisms in four point bending.

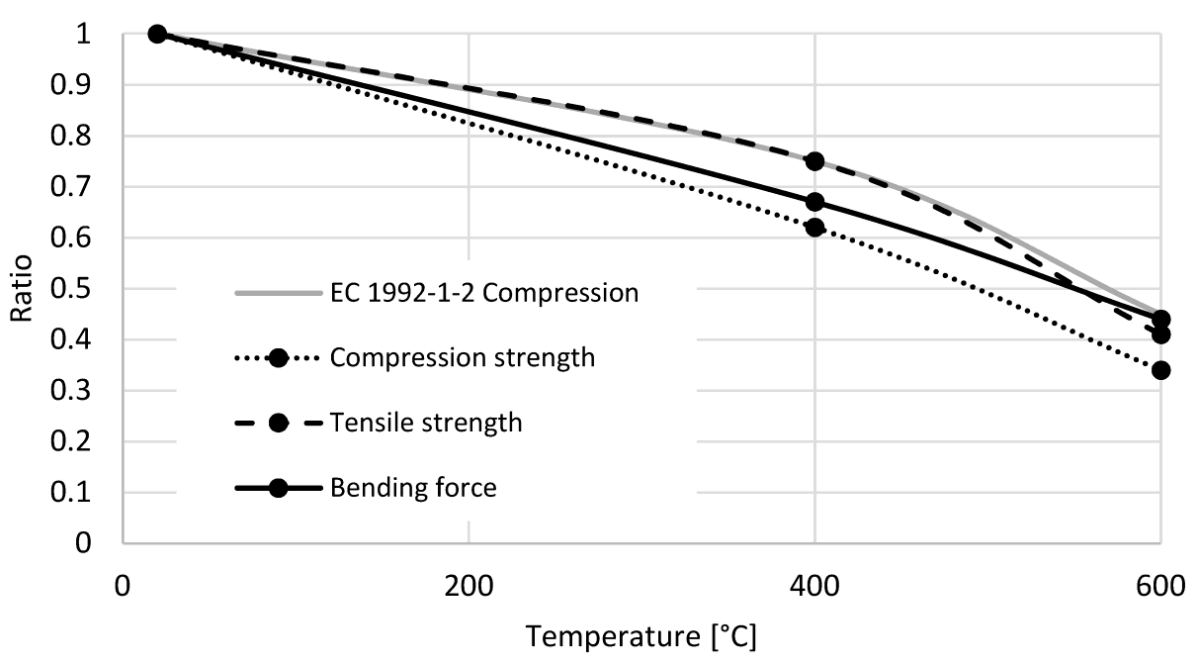

FigurE 13. The dependence of the compression, splitting tensile strength and bending force on the concrete temperature.

reduced by $38 \%$ and $66 \%$, tensile strength is reduced by $25 \%$ and $59 \%$, and ultimate bending force is reduced by $33 \%$ and $56 \%$, in case of $400{ }^{\circ} \mathrm{C}$ and $600{ }^{\circ} \mathrm{C}$ comparing with ambient temperature, respectively. As mentioned above, detailed numeral and graphical results will be published further.

\section{ACKNOWLEDGEMENTS}

This publication was supported by the European social fund, within the framework of realizing the project „Support of inter-sectoral mobility and quality enhancement of research teams at Czech Technical University in Prague", CZ.1.07/2.3.00/30.0034. This publication was supported by the grant of Grant Agency Czech Republic Models of steel and fibre concrete composite columns exposed to fire, GACR 15-19073S.

\section{REFERENCES}

[1] Sukontasukkul, P., Pomchiengpin, W., Songpiriyakij, S.: Post-crack (or post-peak) flexural response and toughness of fibre reinforced concrete after exposure to high temperature, Construction and Building Materials, 24, 2010, p. 1967-1974.

DOI:10.1016/j.conbuildmat.2010.04.003
[2] Salehian, H. et al.: Evaluation of the influence of post-cracking response of steel fibre reinforced concrete (SFRC) on load carrying capacity of SFRC panels. Construction and Building Materials, 73, 2014, p. 289-304. DOI:10.1016/j.conbuildmat.2014.09.043

[3] Meskenas, A. et al.: Simplified technique for constitutive analysis of SFRC, Journal of Civil Engineering and Management, 20(3), 2014, p. 446-453. DOI:10.3846/13923730.2014.909882

[4] Goremikins, V. et al.: Analytical model of composite floors with steel fibre reinforced concrete slab subjected to fire, Journal of Civil Engineering and Management, 2015, p. 1-9. DOI:10.3846/13923730.2015.1027260

[5] Fraternali, F., et al.: Experimental study of the thermo-mechanical properties of recycled PET fiberreinforced concrete. Composite Structures, 93, 2011, p. 2368-2374. DOI:10.1016/j.compstruct.2011.03.025

[6] Fike, R., Kodur. V.: Enhancing the fire resistance of composite floor assemblies through the use of steel fiber reinforced concrete. Engineering Structures, 33(10), 2011, p. 2870-2878. DOI:10.1016/j.engstruct.2011.06.011

[7] Holschemacher, K., Mueller, T., Ribakov, Y.: Effect of steel fibres on mechanical properties of high-strength 
concrete, Materials and Design, 31(5), 2010, p. 2604-2615. DOI:10.1016/j.matdes.2009.11.025

[8] Caggiano, A. et al.: Fracture behaviour of concrete beams reinforced with mixed long/short steel fibres, Construction and Building Materials, 37, 2012, p. 832-840. DOI:10.1016/j.conbuildmat.2012.07.060

[9] Dugenci, O., Haktanir, T., Altun, F.: Experimental research for the effect of high temperature on the mechanical properties of steel fiber-reinforced concrete, Construction and Building Materials, 75, 2015, p. 82-88. DOI:10.1016/j.conbuildmat.2014.11.005

[10] Kim, J., Lee, G., Moon, D.Y.: Evaluation of mechanical properties of steel-fibre-reinforced concrete exposed to high temperatures by double-punch test. Construction and Building Materials, 79, 2015, p. 182-191. DOI:10.1016/j.conbuildmat.2015.01.042

[11] EN 1992-1-2. 2004. Eurocode 2: Design of concrete structures - Part 1-2: General rules - Structural fire design. European committee for standardization, Brussels, 2004.

[12] EN 1993-1-2. 2005. Eurocode 3: Design of steel structures - Part 1-2: General rules - Structural fire design. European committee for standardization, Brussels, 2005.

[13] Sideris, K.K. et al.: Performance of thermally damaged fibre reinforced concretes, Construction and Building Materials, 23, 2009, p. 1232-1239. DOI:10.1016/j.conbuildmat.2008.08.009

[14] CSN EN 12390-3: Testing hardened concrete - part 3: Compressive strength of test specimens. UNMZ, Prague, 2012.

[15] CSN EN 12390-6: Testing hardened concrete - part 6: Tensile splitting strength of test specimens. UNMZ, Prague, 2010.

[16] Bednář, J. et al.: Experiments on membrane action of composite floors with steel fibre reinforced concrete slab exposed to fire. Fire Safety Journal, 59, 2013, p. 111-121. DOI:10.1016/j.firesaf.2013.04.008 